\title{
Unknown syndrome: radial ray defects, omphalocele, diaphragmatic hernia, and hepatic cyst
}

\author{
R Gershoni-Baruch, I Machoul, Y Weiss, S Blazer
}

\begin{abstract}
We present a male infant with a giant omphalocele, diaphragmatic hernia, hepatic cyst, bilateral radioulnar synostosis, absent left thumb, and triphalangeal right thumb.
\end{abstract}

\section{History \\ Prenatal. Polyhydramnios. Giant omphalocele shown by ultrasonography.}

Division of Clinical Genetics, Department of Paediatrics A, Rambam Medical Centre, PO Box 9602, 31096 Haifa, Israel.

R Gershoni-Baruch

Department of Neonatology, Rambam Medical Centre, Haifa, Israel.

I Machoul, Y Weiss, S Blazer

Correspondence to Dr Gershoni-Baruch.

Received for publication 17 August 1989.

Revised version accepted for publication 24 January 1990.
Birth. Caesarean section because of double footling breech presentation. Apgar scores 4 and 8 at one and five minutes.

Family. First child of healthy, unrelated parents. Father aged 34 years, mother aged 27 years.

\section{Medical history}

At birth, primary repair of the giant omphalocele failed. A prosthetic silo inserted into the abdominal wall, followed by gradual reduction of contents. Reoperated at 10 days. Intrahepatic cyst containing clear fluid unroofed. Peritoneal cavity filled with lymphatic fluid draining into the right chest through a right posterior diaphragmatic hernia. Hernia repaired and abdominal wall closed. Died two days after operation. Permission for necropsy not granted.

\section{Clinical examination}

Birth weight $3000 \mathrm{~g}$ (25th centile), length $50 \mathrm{~cm}$ (25th centile), head circumference $35.5 \mathrm{~cm}$ (50th centile). Face unusual, short, downward slanting palpebral fissures, bushy eyebrows, high nasal bridge, short

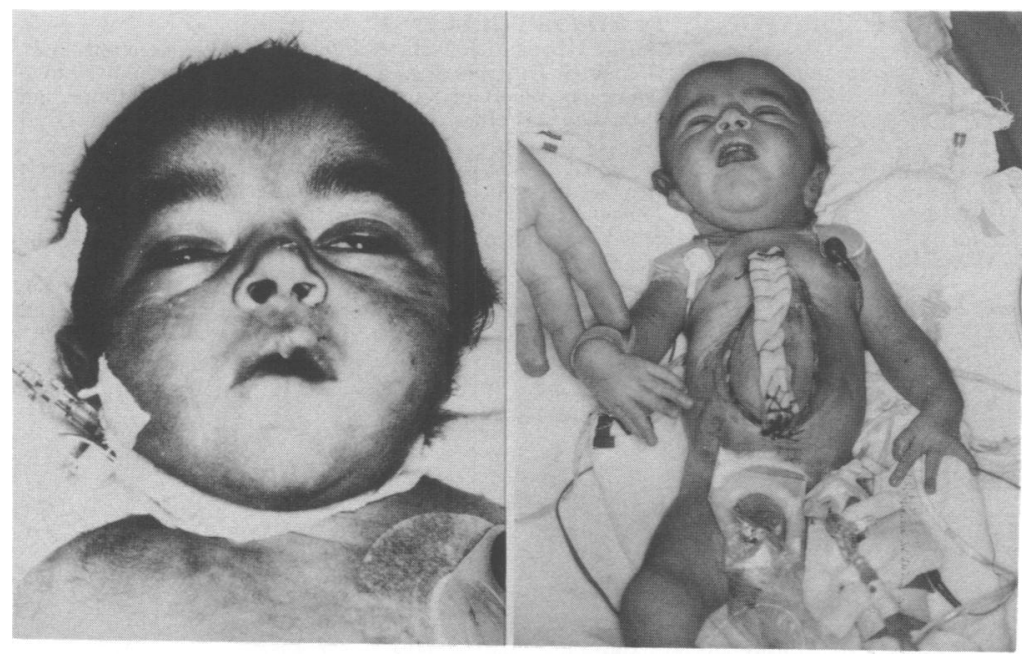

Figure 1 Patient's face and general appearance. 
pointed nose, anteverted nostrils, malar hypoplasia, and micrognathia (fig 1). No lid coloboma, normal eyelashes. Sagittal and metopic sutures wide open, fontanelles large. Ears low set and posteriorly angulated, right ear small and dysplastic. Upper lip thin, long, and downturned with midline beak. Neck short, hairline low, tongue-like extension of hair on both cheeks. Skin thick and hirsute. Elbows flexed, forearms short, left thumb absent, right thumb finger-like (fig 2). Chest bell shaped. Giant omphalocele containing liver and intestines. Genitalia and lower limbs normal. Big toes dorsiflexed.

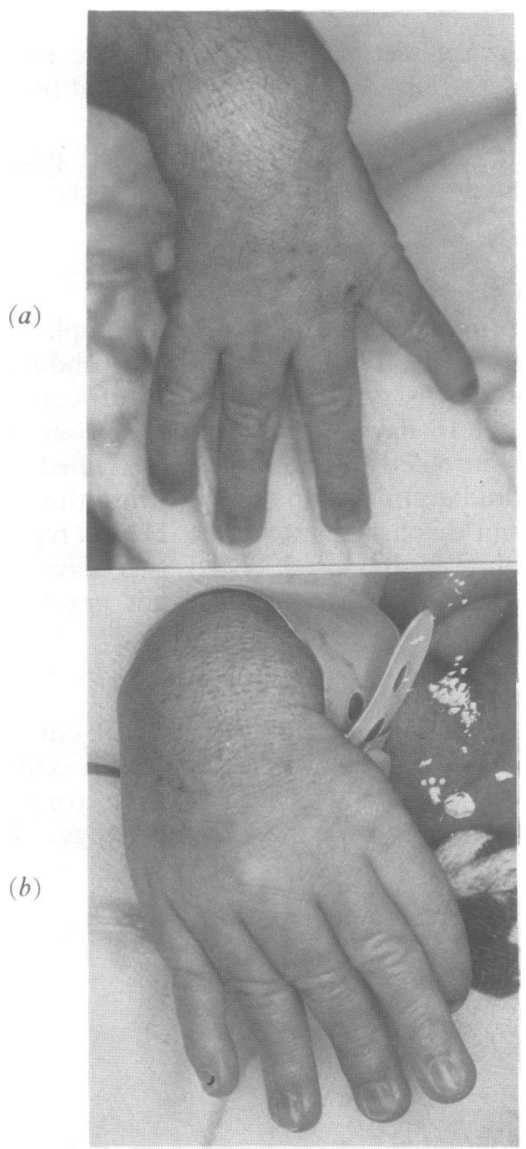

Figure 2 (a) Left hand with absent thumb. (b) Right hand with triphalangeal finger-like thumb.

\section{Investigations}

Normal G banded male karyotype. $X$ rays showed bilateral proximal radioulnar synostosis, absence of right metacarpal and phalanges, and three normal first phalanges. Normal radiographs of feet, spine, and skull. Ultrasonography of the abdomen showed large cystic lesion in a midline liver.

\section{Discussion}

The patient had many facial and acral manifestations typical of Nager syndrome (NS), including short, downward slanting palpebral fissures, high nasal bridge, short nose, small, upturned nostrils, malar and mandibular hypoplasia, dysplastic ear, short neck with low hairline, and tongue-like extension of hair on both cheeks. Other findings, such as hirsutism, bushy eyebrows, a long, thin upper lip with a midline beak, and thick skin, are characteristics of Brachmann-de Lange syndrome (BDLS), but normal birth weight, length, and occipitofrontal circumference and preaxial limb deficiencies are not. The radial ray defects in our patient were very similar to those reported in NS. ${ }^{1-4}$ However, he did not show cleft palate or absence of lashes, and the ears were less dysmorphic and the micrognathia less severe than usually seen in NS. An omphalocele, a diaphragmatic hernia, and a hepatic cyst have not been reported in either NS or BDLS. A diaphragmatic hernia and an omphalocele have recently been described in three patients with Fryns syndrome, ${ }^{5}$ which is characterised by distal digital hypoplasia and is not applicable to our case.

The mode of inheritance of this new syndrome is unknown. It may be sporadic, but autosomal recessive inheritance cannot be ruled out.

1 Temtamy SA, McKusick VA. The genetics of hand malformations. Birth Defects 1978;14:429-37.

2 Halal F, Hermann J, Pallister PD, Opitz JM, Desgranges MF, Grenier $G$. Differential diagnosis of Nager acrofacial dysostosis syndrome: report of four patients with Nager syndrome and discussion of other related syndromes. Am $\mathcal{F}$ Med Genet 1983;14:209-24.

3 Pfeiffer RA, Stoess H. Acrofacial dysostosis (Nager syndrome): synopsis and report of a new case. Am F Med Genet 1983;15: 255-60.

4 Hecht JT, Immken LL, Harris LF, Malini S, Scott CL Jr. The Nager syndrome. Am $\mathcal{Y}$ Med Genet 1987;27:965-9.

5 Evans JA, Keena B, Pantzar T, Friedman JM, Hall JG. Congenital diaphragmatic hernia, coarse facies, and acral hypoplasia: Fryns syndrome. Am $\mathcal{f}$ Med Genet 1989;32:93-9. 